Rio de Janeiro. Ano 15. Volume 22. Número 3. Setembro a Dezembro de 2021

Periódico Quadrimestral da Pós-Graduação Stricto Sensu em Direito Processual da UERJ

Patrono: José Carlos Barbosa Moreira (in mem.). ISSN 1982-7636. pp. 383-398

www.redp.uerj.br

\title{
OBSOLESCÊNCIA E PRECEDENTES JUDICIAIS OBRIGATÓRIOS: UMA ANÁLISE A PARTIR DA DOUTRINA DO STARE DECISIS NO REINO UNIDO E NOS ESTADOS UNIDOS DA AMÉRICA ${ }^{1}$
}

OBSOLESCENCE AND MANDATORY JUDICIAL PRECEDENTS: AN ANALYSIS BASED ON THE DOCTRINE OF STARE DECISIS IN THE UNITED KINGDOM AND THE UNITED STATES OF AMERICA

Frederico Augusto Lepoldino Koehler Juiz Federal do TRF-5a Região, atualmente como Juiz Instrutor no STJ. Mestre em Direito Público pela UFPE. Professor Adjunto da UFPE e do Mestrado Profissional da ENFAM. Membro e Secretário-Adjunto do Instituto Brasileiro de Direito Processual - IBDP. Membro fundador e SecretárioGeral da Associação Norte-Nordeste de Professores de Processo - ANNEP. Recife/PE. E-mail: koehler_koehler@yahoo.com.br

Emiliano Zapata de Miranda Leitão Juiz Federal do TRF da 5. ${ }^{a}$ Região. Mestrando do Mestrado Profissional em Direito do PPGPD/Enfam da Escola Nacional de Formação e Aperfeiçoamento de Magistrados - Enfam. João Pessoa/PB. E-mail: emilzapl@uol.com.br

RESUMO: O presente artigo examina a obsolescência dos precedentes judiciais obrigatórios e seu papel na aplicação da doutrina do stare decisis no Reino Unido e nos Estados Unidos da América. O método da análise conceitual, através de revisão bibliográfica, é utilizado para identificar suas hipóteses. Propõe uma classificação tripartite destas vinculada aos seus potenciais contextos de origem (judicial, legislativa e social).

\footnotetext{
${ }^{1}$ Artigo recebido em 10/04/2021 e aprovado em 10/07/2021.
} 
Revista Eletrônica de Direito Processual - REDP.

Rio de Janeiro. Ano 15. Volume 22. Número 3. Setembro a Dezembro de 2021

Periódico Quadrimestral da Pós-Graduação Stricto Sensu em Direito Processual da UERJ

Patrono: José Carlos Barbosa Moreira (in mem.). ISSN 1982-7636. pp. 383-398

www.redp.uerj.br

Analisa a função desempenhada pela obsolescência na evolução do stare decisis. Conclui que ela serve de ponte entre as finalidades instrumentais e pragmáticas do stare decisis (estabilidade e previsibilidade) e as razões de justiça norteadoras do exercício da atividade jurisdicional.

PALAVRAS-CHAVE: Precedente judicial obrigatório. Stare decisis. Obsolescência. Superação.

ABSTRACT: This paper examines the obsolescence of mandatory court precedents and its role in the application of the stare decisis doctrine in the United Kingdom and the United States of America. The method of conceptual analysis, through literature review, is used to identify its hypotheses. It proposes a tripartite classification of these linked to their potential contexts of origin (judicial, legislative and social). It analyzes the role played by obsolescence in the evolution of stare decisis. It concludes that it serves as a bridge between the instrumental and pragmatic purposes of stare decisis (stability and predictability) and the reasons of justice that guide the exercise of jurisdictional activity.

KEYWORDS: Mandatory judicial precedent. Stare decisis. Obsolescence. Overrulling.

\section{INTRODUÇÃO}

Obsoleto é, em uma de suas acepções, o que é ultrapassado ou antiquado ou se encontra em desuso ${ }^{2}$,sendo obsolescência o processo através do qual se chega à condição de antigo ou ultrapassado ou inútil ou, ainda, o estado do que está próximo de alcançar essa condição ${ }^{3}$. Ambas essas palavras estão vinculadas, em sua origem etimológica ${ }^{4}$, ao verbo

\footnotetext{
2 OBSOLETO. In: Léxico - Dicionário de Português Online. Porto: 7Graus, 2021. Disponível em: <https://www.lexico.pt/obsoleto/>. Acesso em: 22 jan. 2021.

${ }^{3}$ OBSOLESCÊNCIA. In: Dicio - Dicionário Online de Português. Porto: 7Graus, 2021. Disponível em: <https://www.dicio.com.br/obsolescencia/>. Acesso em: 22 jan. 2021.

${ }^{4}$ OBSOLESCENCE. In: Vocabulary.com Dictionary. New York: Vocabulary.com, 2021. Disponível em: <https://www.vocabulary.com/dictionary/obsolescence>. Acesso em: 22 jan. 2021.
} 
Revista Eletrônica de Direito Processual - REDP.

Rio de Janeiro. Ano 15. Volume 22. Número 3. Setembro a Dezembro de 2021

Periódico Quadrimestral da Pós-Graduação Stricto Sensu em Direito Processual da UERJ

Patrono: José Carlos Barbosa Moreira (in mem.). ISSN 1982-7636. pp. 383-398

www.redp.uerj.br

latino "obsolescere", com um dos significados deste vinculando-se à ideia de enfraquecimento ou perda do vigor ou do valor ${ }^{5}$.

A ideia de obsolescência de um precedente judicial obrigatório, ou melhor dizendo, de sua ratio decidendi, vez que esta é a parte vinculante da decisão judicial objeto do precedente $^{6}$, está ligada, portanto, à perda de seu vigor ou de seu valor ou, ainda, ao seu enfraquecimento pela alteração do contexto originalmente existente quando de seu surgimento.

Contudo, na análise de um conceito, a definição do significado da palavra que o expressa não se mostra suficiente, sendo necessário examinar as possibilidades de uso e os usos concretos das palavras ${ }^{7}$, com a finalidade de compreender de forma adequada um conceito através de seus usos em um contexto específico.

Nesse aspecto, para analisar o conceito de obsolescência de um precedente judicial obrigatório, o presente artigo examinará, sob uma perspectiva qualitativa e teórica, com base nos métodos dedutivo e comparativo, o tratamento desse fenômeno no âmbito da doutrina do stare decisis no Reino Unido e nos Estados Unidos da América, estabelecendo sua relação com as regras de superação dos precedentes judiciais obrigatórios e sua classificação a partir dos tipos de alterações contextuais que lhe dão origem.

A análise a ser realizada visa a responder ao questionamento sobre qual a função desempenhada pela obsolescência dos precedentes judiciais obrigatórios na evolução da doutrina do stare decisis na prática judicial inglesa e americana.

São, assim, objetivos do presente artigo: analisar a doutrina do stare decisis no Reino Unido e nos Estados Unidos da América sob o prisma do equilíbrio entre rigidez e flexibilidade na aplicação desta; definir os contornos do instituto da obsolescência dos precedentes judiciais obrigatórios na prática judicial inglesa e americana; identificar as hipóteses classificatórias desse instituto; demonstrar a importância do papel desempenhado pelo instituto da obsolescência dos precedentes judiciais obrigatórios para a evolução da doutrina do stare decisis no Reino Unido e nos Estados Unidos da América.

\footnotetext{
${ }^{5}$ REZENDE, Antônio Martinez de; BIANCHET, Sandra Braga. Dicionário do latim essencial. 2. ed. Belo Horizonte: Autêntica Editora, 2016, p. 253.

${ }^{6}$ FERRAZ, Taís Schilling. O precedente na Jurisdição Constitucional: construção e eficácia do julgamento da questão com repercussão geral. São Paulo: Saraiva, 2017.

${ }^{7}$ WILSON, John. Pensar com conceitos. 2. ed. São Paulo: Martins Fontes, 2005.
} 
Revista Eletrônica de Direito Processual - REDP.

Rio de Janeiro. Ano 15. Volume 22. Número 3. Setembro a Dezembro de 2021

Periódico Quadrimestral da Pós-Graduação Stricto Sensu em Direito Processual da UERJ

Patrono: José Carlos Barbosa Moreira (in mem.). ISSN 1982-7636. pp. 383-398

www.redp.uerj.br

O presente artigo está estruturado em duas partes: "stare decisis - entre a rigidez e a flexibilidade - visão panorâmica no Reino Unido e nos Estados Unidos da América”, na qual serão examinadas a doutrina do stare decisis inglesa e americana e a importância do equilíbrio entre rigidez e flexibilidade em sua aplicação; e "do precedente judicial obrigatório obsoleto - contextos originadores e classificação - relação com a evolução da doutrina do stare decisis", na qual serão analisados o instituto da obsolescência dos precedentes judiciais obrigatórios e sua classificação, bem como demonstrada sua importância para a evolução da doutrina do stare decisis.

\section{STARE DECISIS - ENTRE A RIGIDEZ E A FLEXIBILIDADE - VISÃO PANORÂMICA NO REINO UNIDO E NOS ESTADOS UNIDOS DA AMÉRICA}

Em uma primeira aproximação conceitual, é possível dizer que a doutrina inglesa do stare decisis preconiza a vinculação dos tribunais aos casos decididos por tribunal hierarquicamente superior e, com a exceção da Câmara dos $\operatorname{Lordes}^{8}$, às suas decisões anteriores ${ }^{9}$. No entanto, essa formulação é excessivamente sucinta, pois não explicita que essa vinculação se dá apenas quanto aos elementos do caso anterior identificados como sua ratio decidendi, nem que a regra do stare decisis tem exceções relevantes ${ }^{10}$.

Aprofundando o acima explicado, Cross e Harris esclarecem que a obrigação vinculante de aplicação de um precedente por um juiz está restrita à ratio decidendi do caso anterior, sendo, ainda, condicionada essa vinculação à ausência de possibilidade de estabelecimento de distinção fática (acrescente-se, relevante) entre os fatos do caso presente e aqueles do caso precedente anteriormente julgado ${ }^{11}$.

\footnotetext{
${ }^{8}$ A Câmara dos Lordes (House of Lords), segunda casa parlamentar do Poder Legislativo do Reino Unido, através dos Lords of Appeal in Ordinary ou Law Lords, exercia a função de corte judicial de ápice no sistema judicial do Reino Unido. Ela foi substituída, por força do Constitucional Reform Act 2005, pela Suprema Corte do Reino Unido, a partir de 2009. Confira-se: THE SUPREME Court. Judiciary.uk. 2021. Disponível em: <https://www.judiciary.uk/about-the-judiciary/the-justice-system/the-supreme-court/>. Acesso em: 22 jan. 2021.

${ }^{9}$ CROSS, Rupert; HARRIS, J. W. Precedent in English Law. 4. ed. Oxford: Oxford University Press, 2004. (Clarendon Law Series - Edição do Kindle).

${ }^{10}$ CROSS, Rupert; HARRIS, J. W. Precedent in English Law. 4. ed. Oxford: Oxford University Press, 2004. (Clarendon Law Series - Edição do Kindle).

${ }^{11}$ SCHAUER, Frederick. Thinking Like a Lawyer: A New Introduction to Legal Reasoning. Cambridge, MA: Harvard University Press, 2009. (Edição do Kindle).
} 
Revista Eletrônica de Direito Processual - REDP.

Rio de Janeiro. Ano 15. Volume 22. Número 3. Setembro a Dezembro de 2021

Periódico Quadrimestral da Pós-Graduação Stricto Sensu em Direito Processual da UERJ

Patrono: José Carlos Barbosa Moreira (in mem.). ISSN 1982-7636. pp. 383-398

www.redp.uerj.br

A doutrina do stare decisis traz uma tendência à preservação do decidido anteriormente (casos precedentes) e, portanto, à estabilidade do sistema jurídico, não obstante o fluxo do tempo e as mudanças da sociedade associadas a este. No entanto, a prática dos tribunais ingleses, através da aplicação de diversas técnicas decisórias, permite a evolução do direito, garantindo a preservação da flexibilidade do sistema de precedentes por meio da determinação, de forma relativamente livre e frequente, dos fins e dos limites dos precedentes anteriores em sua aplicação às novas circunstâncias ou da distinção que realizam destas em relação às circunstâncias que consideram essenciais nos casos anteriores ${ }^{12}$.

Assim, a rigidez da regra da vinculação aos precedentes é, na prática judicial, mesmo no âmbito do Reino Unido, contrabalanceada (flexibilizada) por um espaço de manobra do julgador, dentro de certos limites estabelecidos pelo próprio sistema judicial, quanto à adesão concreta à vinculação da decisão do caso atual à ratio decidendi anterior ou, mesmo, à possibilidade de seu afastamento.

Em relação a essa flexibilidade, naquilo em que relevante ao objeto deste artigo, interessam-nos dois mecanismos através dos quais ela pode ser alcançada: a possibilidade de afastamento do stare decisis em relação a uma determinada ratio decidendi, na situação em que uma modificação das circunstâncias possibilita que se apliquem regras distintas; e a possibilidade de abandono de um precedente pela utilização da máxima latina cessante ratione cessat ipsa lex, ou seja, de que a não persistência da razão para a incidência da regra obsta à sua aplicação ${ }^{13}$.

$\mathrm{Na}$ Escócia, inclusive, é expressamente reconhecido que a invalidação ou superação clara da ratio decidendi de um caso anterior por causa legislativa superveniente ou por outra causa similar faz cessar o seu caráter vinculante ${ }^{14}$.

Em sentido similar ao do enunciado acima, cabe citar decisão da Corte de Apelação quanto à aplicação de doutrina de obsolescência dos precedentes judiciais obrigatórios na Inglaterra, no caso Pitalis v. Grant, no sentido de que um tribunal inferior deve, para não deixar de entregar às partes a justiça a que têm direito, reconhecer o caráter obsoleto de uma

\footnotetext{
${ }^{12}$ SESMA, Victoria Iturralde. El precedente en el Common Law. Madrid: Editorial Civitas S. A., 1995.

${ }^{13}$ SESMA, Victoria Iturralde. El precedente en el Common Law. Madrid: Editorial Civitas S. A., 1995.

${ }^{14}$ CROSS, Rupert; HARRIS, J. W. Precedent in English Law. 4. ed. Oxford: Oxford University Press, 2004. (Clarendon Law Series - Edição do Kindle).
} 
Revista Eletrônica de Direito Processual - REDP.

Rio de Janeiro. Ano 15. Volume 22. Número 3. Setembro a Dezembro de 2021

Periódico Quadrimestral da Pós-Graduação Stricto Sensu em Direito Processual da UERJ

Patrono: José Carlos Barbosa Moreira (in mem.). ISSN 1982-7636. pp. 383-398

www.redp.uerj.br

decisão de corte superior, quando perceptível, e decidir o caso em julgamento de acordo com esse reconhecimento ${ }^{15}$. É de ressaltar-se, contudo, a crítica feita por Cross e Harris a essa enunciação pela referida Corte de uma regra geral de exceção ao stare decisis independente da hierarquia judicial. Isso porque ela não mencionou qualquer outro caso com solução similar que pudesse embasá-la firmemente, e pelo repúdio, em outras situações, externado pela Câmara dos Lordes, a exceções aplicadas pela Corte de Apelação à vinculação desta a precedentes superiores.

Não obstante a crítica feita, ao sumariar as exceções ao stare decisis no sistema jurídico inglês, concluem Cross e Harris que, assim como ocorre com as proposições constantes de rationes decidendi estabelecidas de forma implícita (sub silentio ou without argument), ou seja, sem justificativa expressa, que são tidas como não vinculantes, também, pode ser o mesmo entendimento aplicado às rationes decidendi obsoletas.

É importante lembrar a advertência de que a superação de precedentes é uma medida que deve ter caráter excepcional, sob pena de esvaziamento da regra do stare decisis. Em função disso, devem as razões de afastamento da ratio decidendi anterior ser especialmente robustas, não se mostrando suficiente, como regra e sobretudo em relação a precedentes do próprio tribunal ou de um tribunal de igual hierarquia, a demonstração da erronia da decisão superada, salvo, excepcionalmente, quando esta é de grau extremo ${ }^{16}$. Esse grau, ademais, deve ser medido não sob a ótica presente de compreensão de um erro pretérito, mas, sobretudo, pela ponderação da dimensão excepcional deste erro ou de suas consequências ${ }^{17}$. Ou seja, trata-se de um olhar de caráter mais prospectivo do que retrospectivo.

Examinaremos com mais detalhes adiante a relação entre a regra acima enunciada de exceção ao stare decisis quanto ao precedente obsoleto (ou, mais precisamente, cuja ratio decidendi tornou-se obsoleta) e essa exortação de limites mais rígidos para a justificação da superação de um precedente judicial obrigatório.

\footnotetext{
${ }^{15}$ CROSS, Rupert; HARRIS, J. W. Precedent in English Law. 4. ed. Oxford: Oxford University Press, 2004. (Clarendon Law Series - Edição do Kindle).

${ }^{16}$ DUXBURY, Neil. The Nature and Authority of Precedent. Cambridge: Cambridge University Press, 2008. (Edição do Kindle).

${ }^{17}$ SCHAUER, Frederick. Thinking Like a Lawyer: A New Introduction to Legal Reasoning. Cambridge, MA: Harvard University Press, 2009. (Edição do Kindle).
} 
Revista Eletrônica de Direito Processual - REDP.

Rio de Janeiro. Ano 15. Volume 22. Número 3. Setembro a Dezembro de 2021

Periódico Quadrimestral da Pós-Graduação Stricto Sensu em Direito Processual da UERJ

Patrono: José Carlos Barbosa Moreira (in mem.). ISSN 1982-7636. pp. 383-398

www.redp.uerj.br

É reconhecido, quanto ao Direito Americano, que a regra do stare decisis é aplicada de forma menos rígida do que no Reino Unido ${ }^{18}$, ao ponto de a prática atual americana, seja sob o prisma da distinção, seja da superação de precedentes, caracterizar-se por uma flexibilidade chocante para um advogado ou juiz inglês ${ }^{19}$.

A explicação para essa maior flexibilidade na aplicação da doutrina do stare decisis nos Estados Unidos da América é atribuída à multiplicidade de jurisdições (federais e estaduais) e à centralidade da interpretação de normas constitucionais na atividade jurisdicional americana, como ressaltado por Cross e Harris e Sesma. Esses fatores contribuíram, respectivamente, para uma maior complexidade de aplicação da jurisprudência (case-law) americana e para uma postura menos rigorosa na aderência ao caráter vinculante dos precedentes em matéria constitucional, em face da dificuldade do procedimento de emenda à Constituição Americana ${ }^{20}$.

Quanto a essa última característica da doutrina americana do stare decisis em matéria constitucional, ressalta Tribe que uma das razões pelas quais se encontra consolidado o entendimento de que a Suprema Corte Americana deveria poder modificar mais facilmente as decisões de natureza constitucional que acredite seriamente equivocadas, quando em comparação com a mesma situação em relação a normas de simples natureza estatutária (legal), é o fato de ser tão mais difícil emendar a Constituição do que realizar a modificação ou a revogação de uma norma legal ${ }^{21}$.

Em consonância com a maior flexibilidade referida nos parágrafos anteriores, ganham destaque no Direito Americano, de forma mais pacífica do que no Direito Inglês, entre as razões para superação de um precedente, duas hipóteses: a modificação das circunstâncias nas quais se originou o precedente em grau apto a torná-lo obsoleto; e a invocação das mudanças progressivas da cultura moral e social como indicação da perda da aceitabilidade dos valores substantivos nos quais se baseou o precedente ${ }^{22}$.

\footnotetext{
${ }^{18}$ CROSS, Rupert; HARRIS, J. W. Precedent in English Law. 4. ed. Oxford: Oxford University Press, 2004. (Clarendon Law Series - Edição do Kindle).

${ }^{19}$ SESMA, Victoria Iturralde. El precedente en el Common Law. Madrid: Editorial Civitas S. A., 1995.

${ }^{20}$ BARRETT, Amy Coney. Precedent and Jurisprudential Disagreement. Texas Law Review, vol. 91, 2013, p. 1.711-1.737.

${ }^{21}$ TRIBE, Laurence H. American Constitutional Law. 3. ed. New York: Foundation Press, 2000.

${ }^{22}$ SESMA, Victoria Iturralde. EI precedente en el Common Law. Madrid: Editorial Civitas S. A., 1995.
} 
Revista Eletrônica de Direito Processual - REDP.

Rio de Janeiro. Ano 15. Volume 22. Número 3. Setembro a Dezembro de 2021

Periódico Quadrimestral da Pós-Graduação Stricto Sensu em Direito Processual da UERJ

Patrono: José Carlos Barbosa Moreira (in mem.). ISSN 1982-7636. pp. 383-398

www.redp.uerj.br

Mello, referindo-se à realidade doutrinária e jurisprudencial americana, cita, no que se mostra relevante ao presente artigo, três situações aptas a fundamentar a superação de um precedente judicial: primeiro, a sua inexequibilidade prática como decorrência da inoperabilidade da regra nele estabelecida ou da obscuridade desta ou, ainda, da sua desfiguração por distinções arbitrárias em casos subsequentes; segundo, o caráter injusto ou incorreto de um regra por força da alteração de circunstâncias de natureza cultural, política, social, econômica ou tecnológica; e, terceiro, a sua transformação em obsoleto em virtude da modificação dos princípios jurídicos regentes da situação nele decidida ${ }^{23}$ :

Ressalta Mello, contudo, que as razões de justiça que fundamentam a superação de um precedente judicial com base nas hipóteses acima (indicadas como razões de incongruência social ou de inconsistência sistêmica, a depender do caso) devem ser sopesadas com razões de segurança jurídica (confiança no julgado anterior, quebra de isonomia, consequências para a eficiência da administração da justiça, impacto sobre a credibilidade do tribunal). A superação do precedente somente deve ser levada adiante quando os benefícios decorrentes forem maiores do que os prejuízos.

A busca de um adequado equilíbrio no balanceamento entre razões de justiça e razões de segurança jurídica acima mencionado encontra sua justificativa na visão expressa pela Suprema Corte Americana, no caso Payne v. Tennesse, de que o stare decisis é "o caminho preferencial porque promove o desenvolvimento dos princípios legais de forma imparcial, previsível e consistente, fomenta a confiança nas decisões judiciais e contribui para a integridade, real e aparente, do processo judicial" 24 .

Dessa importância legitimadora do stare decisis para o sistema judicial decorre, também, a abordagem daquela Corte na superação de seus precedentes, que enfatiza $o$ caráter excepcional desta medida ${ }^{25}$, mesmo em matéria constitucional, no sentido de evitar, quando possível, a superação de um precedente, ante a natureza drástica desta, preferindo-

23 MELlO, Patrícia Perrone Campos. Precedentes: O desenvolvimento judicial do direito no constitucionalismo contemporâneo. Rio de Janeiro: Renovar, 2008.

24 TRIBE, Laurence H. American Constitutional Law. 3. ed. New York: Foundation Press, 2000, p. 236 (tradução nossa).

${ }^{25}$ SCHAUER, Frederick. Thinking Like a Lawyer: A New Introduction to Legal Reasoning. Cambridge, MA: Harvard University Press, 2009. (Edição do Kindle). 
Revista Eletrônica de Direito Processual - REDP.

Rio de Janeiro. Ano 15. Volume 22. Número 3. Setembro a Dezembro de 2021

Periódico Quadrimestral da Pós-Graduação Stricto Sensu em Direito Processual da UERJ

Patrono: José Carlos Barbosa Moreira (in mem.). ISSN 1982-7636. pp. 383-398

www.redp.uerj.br

se a harmonização ou a distinção de precedentes, como forma de solução de suas contradições, à sua superação de forma absoluta ${ }^{26}$.

De certo modo, a ponderação das razões de justiça e das razões de segurança jurídica acima indicada guarda, também, relação com a observação de Brandeis, Juiz da Suprema Corte Americana, de que "na maioria dos temas é mais importante que [a questão] seja decidida do que que ela seja decidida de forma certa" ${ }^{27}$, em face da relevância da estabilidade jurídica e da confiança na interpretação das normas jurídicas para os destinatários destas. Contudo, como relembra Frederick Schauer em outra passagem da mesma obra ${ }^{28}$ :

[...] mesmo Brandeis reconhecia que assim como é, às vezes, mais importante que as coisas sejam resolvidas do que que elas sejam resolvidas corretamente, também é, às vezes, mais importante que as coisas sejam resolvidas corretamente do que que elas sejam resolvidas incorretamente ou imperfeitamente apenas por razões de pacificação social.

Por fim, é interessante ressaltar que a invocação de razões de justiça para a superação de precedentes judiciais obrigatórios, na forma acima mencionada, é uma exceção à função de autoridade na solução de conflitos judiciais, normalmente, por eles desempenhada. Isso se deve ao fato de que a sua autoridade (vinculante) representa, em regra, impedimento ou afastamento da possibilidade de análise da correção ou justiça do entendimento jurídico (ratio decidendi) neles consagrado, naquilo que se denomina, na esteira da discussão clássica do tema por Hart, de característica de justificação independente do conteúdo da autoridade ${ }^{29}$.

\section{DO PRECEDENTE JUDICIAL OBRIGATÓRIO OBSOLETO - CONTEXTOS ORIGINADORES E CLASSIFICAÇÃO - RELAÇÃO COM A EVOLUÇÃO DA DOUTRINA DO STARE DECISIS}

Mello classifica os precedentes obsoletos, quanto à origem da obsolescência, em: precedentes obsoletos em virtude de mutações sociais, quando a modificação da norma neles

\footnotetext{
${ }^{26}$ TRIBE, Laurence H. American Constitutional Law. 3. ed. New York: Foundation Press, 2000.

${ }^{27}$ SCHAUER, Frederick. Thinking Like a Lawyer: A New Introduction to Legal Reasoning. Cambridge, MA: Harvard University Press, 2009, p. 589 (tradução nossa). (Edição do Kindle).

${ }^{28}$ SCHAUER, Frederick. Thinking Like a Lawyer: A New Introduction to Legal Reasoning. Cambridge, MA: Harvard University Press, 2009, p. 600 (tradução nossa). (Edição do Kindle).

${ }^{29}$ SCHAUER, Frederick. Thinking Like a Lawyer: A New Introduction to Legal Reasoning. Cambridge, MA: Harvard University Press, 2009. (Edição do Kindle).
} 
Revista Eletrônica de Direito Processual - REDP.

Rio de Janeiro. Ano 15. Volume 22. Número 3. Setembro a Dezembro de 2021

Periódico Quadrimestral da Pós-Graduação Stricto Sensu em Direito Processual da UERJ

Patrono: José Carlos Barbosa Moreira (in mem.). ISSN 1982-7636. pp. 383-398

www.redp.uerj.br

expressa decorre da sua inadequação por força da alteração de circunstâncias de natureza cultural, política, social, econômica ou tecnológica por eles regidas; e precedentes obsoletos em virtude de mutações jurídicas, decorrentes da modificação dos princípios jurídicos regentes das situações neles decididas, que podem provocar sua revogação, pois a natureza sistemática e axiológica do ordenamento jurídico conduz à necessidade de evolução dos precedentes judiciais em consonância com as alterações normativas, valorativas e finalísticas do direito aplicável às novas circunstâncias por eles regidas ${ }^{30}$.

Quanto a esse último tipo de precedente obsoleto, cita a decisão da Suprema Corte Americana no caso Lawrence v. Texas, indicando que nela houve a superação do precedente em Bowers v. Hardwich, no qual havia sido considerada válida uma lei da Geórgia sobre o crime de sodomia, sendo essa superação realizada com base no fundamento de que decisões posteriores haviam conduzido à evolução dos princípios jurídicos em sentido divergente ${ }^{31}$.

Embora pertinentes os aspectos da obsolescência dos precedentes judiciais obrigatórios explicitados pela classificação acima, o seu cotejo com a visão panorâmica desse fenômeno na doutrina do stare decisis do Reino Unido e dos Estados Unidos anteriormente analisada evidencia uma potencial incompletude. Fazemos referência, aqui, à não abrangência das alterações jurídicas legislativas como fonte dessa obsolescência, ou, então, ao englobamento dessas alterações sob a mesma rubrica das alterações de interpretação/construção judicial de normas jurídicas (precedentes obsoletos em virtude de mutações jurídicas).

Diante dessa constatação, parece adequado propor uma classificação alternativa e que melhor capture e distinga as três potenciais origens de obsolescência dos precedentes judiciais obrigatórios identificáveis no exame dos contextos britânico e americano acima realizado:

I - as alterações contextuais externas à função legislativa e judicial, ou seja, decorrentes de alterações da sociedade, sejam de natureza cultural, política, social, econômica ou tecnológica;

30 MELlo, Patrícia Perrone Campos. Precedentes: O desenvolvimento judicial do direito no constitucionalismo contemporâneo. Rio de Janeiro: Renovar, 2008.

31 MELlO, Patrícia Perrone Campos. Precedentes: O desenvolvimento judicial do direito no constitucionalismo contemporâneo. Rio de Janeiro: Renovar, 2008. 
Revista Eletrônica de Direito Processual - REDP.

Rio de Janeiro. Ano 15. Volume 22. Número 3. Setembro a Dezembro de 2021

Periódico Quadrimestral da Pós-Graduação Stricto Sensu em Direito Processual da UERJ

Patrono: José Carlos Barbosa Moreira (in mem.). ISSN 1982-7636. pp. 383-398

www.redp.uerj.br

II - as alterações contextuais do desenvolvimento normativo legislativo, ou seja, oriundas de normas de origem não judicial e, portanto, não decorrentes da atividade jurisdicional (interpretativa ou criativa dos tribunais e juízes);

III - e as alterações contextuais resultantes do desenvolvimento normativo judicial, ou seja, da interpretação (e/ou criação) de normas jurídicas, incluindo os precedentes judiciais no curso da atividade jurisdicional.

A obsolescência judicial dá origem ao precedente judicialmente obsoleto e este, por sua vez, diz respeito às hipóteses já antes mencionadas acima de inexequibilidade prática como decorrência da inoperabilidade da regra nele estabelecida ou da obscuridade desta ou, ainda, da sua desfiguração por distinções arbitrárias em casos subsequentes e, também, da modificação dos princípios jurídicos regentes da situação nele decidida na hipótese específica de evolução jurisdicional/jurisprudencial da interpretação/construção destes ${ }^{32}$.

O caráter distintivo desse tipo de obsolescência em relação aos demais é a origem jurisdicional do enfraquecimento/perda do valor ou vigor do precedente judicial obrigatório. Assim, cuida-se de fenômeno que se manifesta como consequência do próprio desenvolvimento da visão judicial sobre o conteúdo normativo expresso na ratio decidendi que se torna obsoleta, seja do ponto de vista operacional (exequibilidade), seja do ponto de vista do seu próprio fundamento jurídico.

O julgamento do caso College Savings Bank v. Florida pela Suprema Corte Americana exemplifica uma situação em que, na visão da maioria da Corte, entre os fundamentos para a superação de um precedente anterior daquela mesma Corte (Parden $v$. Terminal Railway Co. of Alabama), encontrava-se a obsolescência judicial desse anterior precedente, como exemplificado no seguinte trecho do voto do Juiz Scalia, que redigiu a opinião da Corte, citado por Gerhardt ${ }^{33}$ :

Nós achamos que o experimento de renúncia construtiva de Parden foi mal concebido, e não vemos qualquer mérito na tentativa de salvar qualquer remanescente dele... Parden rompeu de forma clara com outros casos, e é fundamentalmente incompatível com casos posteriores. Nós nunca aplicamos a regra de Parden a qualquer outra norma legal, e, de fato,

32 MELLO, Patrícia Perrone Campos. Precedentes: O desenvolvimento judicial do direito no constitucionalismo contemporâneo. Rio de Janeiro: Renovar, 2008.

${ }^{33}$ GERHARDT, Michael J. The Power of Precedent. New York: Oxford University Press Inc, 2008, p. 621 - posição (tradução nossa). (Edição do Kindle). 
Revista Eletrônica de Direito Processual - REDP.

Rio de Janeiro. Ano 15. Volume 22. Número 3. Setembro a Dezembro de 2021

Periódico Quadrimestral da Pós-Graduação Stricto Sensu em Direito Processual da UERJ

Patrono: José Carlos Barbosa Moreira (in mem.). ISSN 1982-7636. pp. 383-398

www.redp.uerj.br

reduzimos a amplitude do caso em opinião subsequente na qual foi objeto de consideração. Em resumo, Parden persiste como uma anomalia na jurisprudência da imunidade soberana, e, em realidade, na jurisprudência do direito constitucional. Hoje, nós largamos o outro sapato: o que quer que ainda remanescia de nossa decisão [em Parden] é superado de forma expressa.

Assim, na opinião da Suprema Corte Americana acima mencionada, a regra naquele momento superada mostrava-se incompatível com a própria jurisprudência da Corte anterior e posterior ao precedente na qual encartada. Isso, ademais, era ressaltado, de forma mais evidente ainda, pelo fato de ela não ter sido aplicada concretamente após o seu surgimento, mas, ao contrário, ter tido seu alcance restringido em caso subsequente.

Importante, nesse ponto, ressaltar que um dos indícios potenciais da obsolescência judicial de um precedente pode, exatamente, ser percebido pelo excessivo estreitamento de sua ratio decidendi em julgados posteriores que o afirmam, mas, ao mesmo tempo, o enfraquecem em seu vigor normativo através de distinções que, no limite, podem conduzir à sua descaracterização, preparando o terreno para a sua superação ${ }^{34}$.

Esse fenômeno (enfraquecimento de precedentes através do estreitamento de sua ratio decidendi), decorre da já acima mencionada reticência do tribunal em superar seus precedentes. Dá-se preferência, para preservar o máximo possível o stare decisis, à harmonização ou distinção de precedentes contraditórios. Contudo, o progressivo recurso a essa técnica de salvação pode, como referido, sinalizar a obsolescência judicial do precedente e, assim, conduzir, no fim, ao reconhecimento de ter chegado o momento de abandoná-lo em definitivo.

Por outro lado, os fatos de a inconsistência com precedentes posteriores ser a mais comum causa de superação de precedentes pela Suprema Corte Americana, e de que a inexequibilidade ser a terceira causa mais comum, demonstra a importância da obsolescência judicial como elemento justificador do abandono do stare decisis na jurisprudência constitucional americana ${ }^{35}$.

\footnotetext{
${ }^{34}$ GERHARDT, Michael J. The Power of Precedent. New York: Oxford University Press Inc, 2008. (Edição do Kindle).

${ }^{35}$ GERHARDT, Michael J. The Power of Precedent. New York: Oxford University Press Inc, 2008. (Edição do Kindle).
} 
Revista Eletrônica de Direito Processual - REDP.

Rio de Janeiro. Ano 15. Volume 22. Número 3. Setembro a Dezembro de 2021

Periódico Quadrimestral da Pós-Graduação Stricto Sensu em Direito Processual da UERJ

Patrono: José Carlos Barbosa Moreira (in mem.). ISSN 1982-7636. pp. 383-398

www.redp.uerj.br

A obsolescência legislativa, por sua vez, origina o precedente legislativamente obsoleto, que é aquele cuja norma jurídica embasadora de sua ratio decidendi sofreu alteração ou revogação legislativa de forma a infirmar a validade da regra nele construída quanto a seus fundamentos normativos ou ao seu alcance prático, quando substancialmente esvaziado.

O reconhecimento, contudo, da ocorrência da obsolescência legislativa de um precedente deve ser realizado com cautela e atenção específica para a distinção entre as antinomias aparentes e reais e para as possibilidades de sua solução sem o necessário abandono, total ou parcial, da ratio decidendi do precedente, hipótese, esta última, em que, concretamente, se tem apenas uma falsa aparência (portanto, superável) de obsolescência legislativa.

Por sua vez, da obsolescência social surge o precedente socialmente obsoleto, que é aquele em relação ao qual alterações fáticas e axiológicas relevantes na sociedade (também denominadas de mutações sociais ${ }^{36}$ conduzem ao surgimento de razões dependentes de conteúdo (razões de justiça ou substantivas ou de primeira ordem) ${ }^{37}$ extraordinariamente fortes (compelling reasons) ${ }^{38}$, que esvaziam o vigor ou valor da ratio decidendi originalmente nele posta, justificando o seu abandono jurisdicional.

Duas das controvérsias constitucionais mais importantes da história da Suprema Corte Americana, inclusive, fazem referência, como fundamento para a superação de precedentes anteriores, também, à obsolescência social daqueles ${ }^{39}$ :

- o caso West Coast Hotel Co. v. Parrish, no qual superada a doutrina de proteção da liberdade contratual contra intervenções normativas estatais de regulação das relações de trabalho estabelecida em Lochner v. New York, em função das modificações econômicas decorrentes da Grande Depressão iniciada em 1929 e das medidas estatais necessárias ao seu enfrentamento (New Deal);

36 MELlo, Patrícia Perrone Campos. Precedentes: O desenvolvimento judicial do direito no constitucionalismo contemporâneo. Rio de Janeiro: Renovar, 2008.

${ }^{37}$ SCHAUER, Frederick. Thinking Like a Lawyer: A New Introduction to Legal Reasoning. Cambridge, MA: Harvard University Press, 2009. (Edição do Kindle).

38 MELlo, Patrícia Perrone Campos. Precedentes: O desenvolvimento judicial do direito no constitucionalismo contemporâneo. Rio de Janeiro: Renovar, 2008.

39 MELlO, Patrícia Perrone Campos. Precedentes: O desenvolvimento judicial do direito no constitucionalismo contemporâneo. Rio de Janeiro: Renovar, 2008. 
Revista Eletrônica de Direito Processual - REDP.

Rio de Janeiro. Ano 15. Volume 22. Número 3. Setembro a Dezembro de 2021

Periódico Quadrimestral da Pós-Graduação Stricto Sensu em Direito Processual da UERJ

Patrono: José Carlos Barbosa Moreira (in mem.). ISSN 1982-7636. pp. 383-398

www.redp.uerj.br

- e o caso Brown v. Board of Education, que invalidou, no âmbito da educação, a doutrina dos "separados mais iguais" instituída em Plessy v. Ferguson em virtude das mudanças culturais quanto ao papel da educação e aos efeitos da segregação racial ocorridas no intervalo entre o momento de julgamento desses dois precedentes.

Fica perceptível, por fim, a partir do exame acima procedido, que a obsolescência dos precedentes judiciais obrigatórios, nas suas diversas modalidades, ostenta uma função importante na evolução do stare decisis, vez que serve à construção de padrões consistentes de fundamentação de hipóteses de superação daqueles. Esses padrões dialogam com as finalidades instrumentais e pragmáticas do stare decisis (estabilidade e previsibilidade), conforme qualificadas por Tribe ${ }^{40}$, mantendo uma ponte entre estas e as razões de justiça que devem nortear o exercício da jurisdição.

\section{CONCLUSÃO}

Demonstrou-se, no presente artigo, que a obsolescência de precedentes judiciais obrigatórios, conceito vinculado à perda de vigor/valor ou enfraquecimento da ratio decidendi daqueles, é fenômeno reconhecido na prática judicial da doutrina do stare decisis do Reino Unido e dos Estados Unidos da América, constituindo-se em razões substantivas para a superação daqueles.

Da análise procedida, estabeleceu-se que sua classificação deve atender à natureza tripartite de suas potenciais origens no exame dos contextos britânico e americano do stare decisis, em parcial divergência com o critério classificatório bipartite na doutrina nacional examinada, do que resulta a existência das categorias de:

- obsolescência judicial, quando caracterizada a ausência de exequibilidade prática do precedente judicial como resultado da inoperabilidade da regra nele estabelecida, da obscuridade desta ou da sua desfiguração por distinções arbitrárias em casos posteriores, bem como da alteração dos princípios jurídicos regentes da situação nele decidida na hipótese de evolução jurisdicional/jurisprudencial da interpretação/construção destes;

\footnotetext{
${ }^{40}$ TRIBE, Laurence H. American Constitutional Law. 3. ed. New York: Foundation Press, 2000.
} 
Revista Eletrônica de Direito Processual - REDP.

Rio de Janeiro. Ano 15. Volume 22. Número 3. Setembro a Dezembro de 2021

Periódico Quadrimestral da Pós-Graduação Stricto Sensu em Direito Processual da UERJ

Patrono: José Carlos Barbosa Moreira (in mem.). ISSN 1982-7636. pp. 383-398

www.redp.uerj.br

- obsolescência legislativa, na hipótese de a norma jurídica embasadora da ratio decidendi do precedente judicial obrigatório ter sofrido alteração ou revogação legislativa de forma a infirmar a validade da regra nele construída quanto a seus fundamentos normativos ou ao seu alcance prático, quando substancialmente esvaziado este;

- e obsolescência social, na situação de ocorrência de alterações fáticas e axiológicas relevantes na sociedade (mutações sociais) conducentes ao surgimento de razões dependentes de conteúdo (razões de justiça ou substantivas ou de primeira ordem) extraordinariamente fortes (compelling reasons) aptas a esvaziar o vigor ou valor da ratio decidendi originalmente nele posta, justificando o seu abandono jurisdicional.

Por fim, quanto ao questionamento (problema) motivador do presente artigo, restou evidenciado que a obsolescência dos precedentes judiciais obrigatórios tem função relevante na evolução da própria sistemática do stare decisis na prática judicial inglesa e americana, ao contribuir, ao mesmo tempo, para a sua flexibilidade e para a preservação de sua integridade institucional mediante a construção de padrões consistentes de fundamentação da superação dos precedentes judiciais obrigatórios. Nessa função, serve o instituto da obsolescência de ponte entre a estabilidade e a previsibilidade, como finalidades instrumentais e pragmáticas do stare decisis, e as razões de justiça norteadoras do exercício da atividade jurisdicional.

\section{REFERÊNCIAS}

BARRETT, Amy Coney. Precedent and Jurisprudential Disagreement. Texas Law Review, vol. 91, p. 1.711-1.737, 2013.

CROSS, Rupert; HARRIS, J. W. Precedent in English Law. 4. ed. Oxford: Oxford University Press, 2004. (Clarendon Law Series - Edição do Kindle).

DUXBURY, Neil. The Nature and Authority of Precedent. Cambridge: Cambridge University Press, 2008. (Edição do Kindle).

FERRAZ, Taís Schilling. O precedente na Jurisdição Constitucional: construção e eficácia do julgamento da questão com repercussão geral. São Paulo: Saraiva, 2017. 
GERHARDT, Michael J. The Power of Precedent. New York: Oxford University Press Inc, 2008. (Edição do Kindle).

MELLO, Patrícia Perrone Campos. Precedentes: O desenvolvimento judicial do direito no constitucionalismo contemporâneo. Rio de Janeiro: Renovar, 2008.

OBSOLESCENCE. In: Vocabulary.com Dictionary. New York: Vocabulary.com, 2021. Disponível em: <https://www.vocabulary.com/dictionary/obsolescence>. Acesso em: 22 jan. 2021.

OBSOLESCÊNCIA. In: Dicio - Dicionário Online de Português. Porto: 7Graus, 2021. Disponível em: <https://www.dicio.com.br/obsolescencia/>. Acesso em: 22 jan. 2021.

OBSOLETO. In: Léxico - Dicionário de Português Online. Porto: 7Graus, 2021. Disponível em: <https://www.lexico.pt/obsoleto/>. Acesso em: 22 jan. 2021.

REZENDE, Antônio Martinez de; BIANCHET, Sandra Braga. Dicionário do latim essencial. 2. ed. Belo Horizonte: Autêntica Editora, 2016.

SCHAUER, Frederick. Thinking Like a Lawyer: A New Introduction to Legal Reasoning. Cambridge, MA: Harvard University Press, 2009. (Edição do Kindle).

SESMA, Victoria Iturralde. El precedente en el Common Law. Madrid: Editorial Civitas S. A., 1995.

THE SUPREME Court. Judiciary.uk. 2021. Disponível em: <https://www.judiciary.uk/about-the-judiciary/the-justice-system/the-supremecourt/>. Acesso em: 22 jan. 2021.

TRIBE, Laurence H. American Constitutional Law. 3. ed. New York: Foundation Press, 2000.

WILSON, John. Pensar com conceitos. 2. ed. São Paulo: Martins Fontes, 2005. 